\title{
20 LEGITIMACY MANAGEMENT AND TRUST IN OFFSHORING INFORMATION TECHNOLOGY SERVICES
}

\author{
Michael Barrett \\ Judge Business School \\ Cambridge University \\ Cambridge, UK \\ C. R. Hinings \\ School of Business \\ University of Alberta \\ Edmonton, $A B$ Canada \\ Eivor Oborn \\ Judge Business School \\ Cambridge University \\ Cambridge, UK
}

\begin{abstract}
Our study examines the evolution of offshoring of information technology services between a multinational telecommunications firm and Indian vendors. The firm's strategy sought to access critical resources of talented software professionals at low cost and to facilitate growth in a highly competitive telecommunications sector. Legitimacy management proved critical in explaining the evolution of this offshoring arrangement between a client firm and its four Indian vendors. Our findings surface the strategies and activities adopted by proponents in their challenge of gaining, maintaining, building, and repairing legitimacy. We examine how the subsequent reactions and interactions of other audiences iteratively influenced the legitimacy dynamics of offshoring. We also contribute an understanding of the role of trust in the challenges of managing legitimacy, and conclude with practical implications for institutionalizing offshoring arrangements.
\end{abstract}

Please use the following format when citing this chapter:

Barrett, M., Hinings, C. R., and Oborn, E., 2008, in IFIP International Federation for Information Processing, Volume 267, Information Technology in the Service Economy: Challenges and Possibilities for the $21^{\text {st }}$ Century, eds. Barrett, M., Davidson, E., Middleton, C., and DeGross, J. (Boston: Springer), pp. $283-299$. 
Keywords Offshoring, legitimacy, institutionalization, trust, IT services

\section{INTRODUCTION}

The Indian information technology enabled services industry grew at more than 50 percent per annum between 2000 and 2003, with revenue growth of 43 percent to U.S.\$5.1 billion in 2004-05, up from U.S.\$3.6 billion the previous year (NASSCOM 2005). By 2008, the expected potential of exports is projected to be in the range of $\$ 21$ billion to \$24 billion (the Indian government's Department of IT, Annual Report 200304), employing upwards of 1.2 million people.

Rapid changes in technology and global competition over the last decade have radically increased the needs of high technology firms to develop innovative relationships with vendor firms for software development (Nicholson and Sahay 2001). These vendorclient relationships are often emergent and ambiguous, evolving from cooperative relationships such as recurrent contracting (Ring and Van de Ven 1992) to relational contracting or strategic alliances. The evolution of these relationships may involve closer collaboration as vendors become partners, and an "extension of the client firm" (Humphreys 1998).

While recent research has recognized the importance of trust and control in offshoring relationships (Sabherwal 1999; Sahay et al. much less is known about the actual process of evolution of the relationship at the level of work practice (Barley and Kunda 2001; Orlikowski 2000). In our case study, offshoring was referred to as externalization or the extension of the client firm through outsourcing relationships with Indian vendors. We focus on the challenges of managing legitimacy and highlight the different dimensions of trust at play in the evolution of offshoring relationships.

Surprisingly little empirical research has uncovered the challenges of legitimacy management (Suchman 1995) or how practices can be more or less legitimated over time in the process of institutionalization (Colyvas and Powell 2006). In our study on the evolution of offshoring practices involving multiple organizations, network legitimacy is particularly important (Human and Provan 2000; Provan et al. Doyle 2004). We build on this emerging stream of literature by empirically analyzing how legitimacy of a network of multiple organizations changes over time. In so doing, we examine a hitherto neglected but important area: the role of trust in these legitimacy processes, which is particularly important at this network level. We ask the following questions: What are the various strategies and activities adopted by proponents in managing the challenges of legitimacy during the institutionalization of offshoring IT services? What role does trust play in the ensuing legitimacy dynamics?

In the next section, we discuss our key concepts, namely legitimacy and trust. We then describe the research process used in our longitudinal case study of an offshoring relationship between a North American telecommunications firm, Globalco, and its Indian vendors. Our case analysis illuminates the strategies and activities deployed by actors of the clients' outsourcing department in managing legitimacy challenges, and the reactions of other audiences within the firm and across vendors. We follow with a discussion of the role of trust in managing these legitimacy challenges at Globalco, and conclude with practical implications for institutionalizing offshoring IT services. 


\section{LEGITIMACY AND TRUST}

\subsection{Legitimacy}

Legitimacy is commonly referred to being largely taken for granted, and accepted as appropriate and right by external constituencies (Aldrich and Fiol 1994). There are both evaluative and cognitive dimensions of legitimacy, which can be holistically incorporated in defining legitimacy as "a generalized perception or assumption that the actions of an entity are desirable, proper, or appropriate within some socially constructed system of norms, values, beliefs, and definitions" (Suchman 1995, p. 574).

A key feature of legitimacy is that practices, beliefs, or rules are reproduced without significant mobilization and are resistant to contestation (Colyvas and Powell 2006; Jepperson 1991). Legitimacy is conferred when influential constituencies or audiences perceive actors as being in alignment with a shared social reality, which can be an organization, or a network of multiple organizations that seek to operate from a common meaning system, or society at large. Thus, audiences perceive the legitimate practice as not only more worthy, but more meaningful and trustworthy (Suchman 1995).

Somewhat ironically, despite its centrality, legitimacy has been largely taken for granted and is in need of conceptual development (Colyvas and Powell 2006; Suchman 1995). In particular, there is little work on the process by which legitimacy is gained, maintained, and lost (Baum and Powell 1995; Suchman 1995; Suddaby and Greenwood 2005).

Suchman (1995) synthesized the role actors play in skillful legitimacy management, drawing on a selection of strategies aimed at gaining, maintaining, and repairing legitimacy. For example, actors may gain legitimacy by manipulating the environment through the enactment of their claims in carrying out a successful institutionalization project (DiMaggio and Powell 1991). Strategies for maintaining legitimacy broadly include perceiving future changes and protecting past accomplishments. The former focuses on facilitating the organization's ability to recognize audience reactions and foresee emerging yet unforeseen challenges while the latter can involve managers actively policing internal operations for reliability and responsibility, stockpiling trust.

Actors can also creatively reestablish legitimacy or repair legitimacy following a crisis or significant disruption. Managers may decide to deny, excuse, or justify the threat, although they do so at the risk of depleting long-term legitimacy reserves. Alternatively, managers may accept these threats and attempt to facilitate relegitimation (Suchman 1995).

Recent research on network legitimacy theory focuses on the processes used by interorganizational networks to establish legitimacy (Provan et al. 2004). Human and Provan (2000), in their study of manufacturing networks, highlight that achieving legitimacy requires that both outside constituents/audiences and inside member organizations view the network concept as an acceptable form for organizing multiple organizations and providing services. The network also has to be viewed as a distinct entity with its own identity. They also identified a third dimension of legitimacy, interaction, which recognizes the need for cooperation among organizations.

In our study, we focus on the evolution of the offshoring department and the efforts of its staff to establish and build legitimacy for offshoring. We propose that the success- 
ful evolution of offshoring arrangements requires legitimacy management strategies by key actors to establish network legitimacy at the form, entity, and interaction levels. Furthermore, we suggest that ongoing active trust is central to the development of legitimacy at each of these levels and we, therefore, turn to the literature on trust.

\subsection{Trust}

While a definition of trust remains elusive (Das and Teng 2001), it is widely recognized as a key element in collaborative interorganizational relationships (Newell and Swan 2000; Ring 1996). Trust recognizes the need for risk-taking in the context of dependent interpersonal relations. For example, Mayer et al. (1995) suggest that trust must include a willingness to take a risk in the relationship and to be vulnerable. Dimensions of trust have been categorized as cognition based, affect based and system trust, which we now discuss in turn.

Cognition-based trust, such as competence trust, depends on the predictability of one party to forecast another party's behavior. This dimension of trust is emergent, with the trustor granting trust based on prior experiences that demonstrate predictable target behavior. As such, cognition-based trust building requires information or knowledge about past actions or knowledge-based trust (Shapiro et al. 1992). Goodwill trust, another element of cognitive trust, focuses on one party's perception of the intentions of the other party to demonstrate a special concern for others' interests above their own (Barber 1983; Doney et al. 1998). Parties exhibiting goodwill trust in a supplier-client relationship will be prepared to make investments to extend and support a range of tasks and to continue developing the relationship (Humphreys 1998).

Another form of cognitive-based trust, calculative trust, suggests that developing trust involves a calculative, rational process whereby one party calculates the costs and/or rewards of another party cheating or cooperating in a relationship (e.g., Dasgupta 1988; Williamson 1985). Trust in business relationships often develops first on a calculative basis (Child 1998, 2001), as parties assess what they might get from the relationship, and what their risks and their vulnerabilities are likely to be (Doney et al. 1998). One type of calculative trust (Shapiro et al. 1992), deterrence-based trust, suggests that people will do what they say they will do to the extent to which the deterrent, whether it be contractual penalties or increased monitoring of behavior (Humphreys 1998), is clear, possible, and likely to occur (Doney et al. 1998).

In contrast to cognitive-based trust, affect-based trust recognizes attitudes, behaviors, (Lewicki and Bunker 1995), and their importance in the evolution of trust. At each exchange point, affect-based trust influences the ongoing experience and meaning of the relationship. Two types of affect-based trust have been distinguished in the literature. First, characteristic-based trust relies on ascribed characteristics such as ethnic backgrounds as good reasons to trust (Zucker 1986) while identification-based trust (Shapiro et al. 1992) suggests that trust develops when partners identify with shared values and norms at a bonding phase of the relationship (Child 2001).

System trust (Luhmann 1979) is an important complement to the above-mentioned dimensions of interpersonal trust. Giddens (1990) suggests that the sustaining of trust is challenging in globalization as the proliferation of systems of expertise (e.g., standardized company procedures and practices) leads to the disembedding (or stretching) 
of social relations whereby social relations are lifted out from local contexts of interaction. At the same time, there are reembedding processes which facilitate trust maintenance at the access points, which, Giddens suggests, provide the link between personal and system trust. These access points are typically found in boundary spanning roles such as relationship managers (Sydow and Windeler 1998). These individuals often serve as representatives to reinforce trust in systems such as standards, rules, and procedures comprising the system.

Our theoretical position starts with and builds on the above literature on trust and legitimacy. We suggest that the different dimensions of trust built up through interaction are vital in supporting legitimacy management strategies throughout the evolution of the offshoring arrangement.

\section{RESEARCH PROCESS}

We conducted a qualitative longitudinal case study of an offshoring relationship between a multinational company we call Globalco and its four Indian partner firms to examine the complexities and dynamics of collaboration (Arino and De la Torre 1998; de Rond and Bouckikhi 2004). The field study sought to understand Globalco's initial formation and subsequent development of offshoring arrangements.

Our real-time study took place over 2 years with prior historical reconstruction over 10 years of the offshoring arrangement. We sought to develop an in-depth understanding of the actions and perceptions of different actors within the firms who influenced the formation and development of the offshoring arrangements. We approached the concept of process as a sequence of events and actions that describes how things change over time (Giddens 1984; Pettigrew 1990).

\subsection{Globalco and its Four Indian Vendors}

Globalco is a North American multinational firm in the telecommunications industry providing a wide range of networking and infrastructure products and services to customers in 150 countries. At the turn of the $21^{\text {st }}$ century, it had revenues of approximately U.S.\$20 billion and employed over 60,000 people. During this period, Globalco faced intense competitive pressure within its dynamic deregulated industry. As such, there were significant demands for technological expertise in the development of new products along with the maintenance of existing large systems. To this end, they developed an externalization (offshoring) vision in 1991, which sought to develop contractor relationships with firms in India, China, Russia, Vietnam, and the Philippines to support their work.

We carried out a historical reconstruction of the development of the offshoring strategy with a particular focus on Globalco's relationship with its Indian vendors, three of whom were located in Bangalore and one in Mumbai. Vendors varied in size and expertise and offered a variety of services to meet the needs of Globalco. For example, the largest vendor was the IT consultancy of an Indian multinational, and one of the pioneers of offshore outsourcing. This firm was the least dependent on Globalco for business, and was able to provide large numbers of coders and developers predominantly 
for software development activities. In contrast, the smallest vendor depended on Globalco for over 60 percent of its revenues. This firm provided highly trained personnel to develop niche digital signal processing solutions for Globalco. The other vendors were rapidly growing mid-sized vendors offering a mix of services, which were successfully developing an international reputation in IT services offshoring.

\subsection{Data Collection and Analysis}

Our first phase of interviews took place in Globalco's Office in North America. We interviewed four directors of the newly established offshoring office, ORD, responsible for the implementation of the outsourcing programs and three senior research and development managers working with teams in the Indian partner firms. A second phase took place 6 months later in Bangalore and Mumbai where a total of 45 semi-structured interviews were conducted with a range of individuals across the 4 Indian vendor firms including CEO's, project managers, software engineers, and relationship managers. In keeping with our longitudinal approach to the study of these offshoring relationships, we conducted a third round of 30 interviews a year later in North America and a final set with the Indian partners shortly thereafter. We also collected and analyzed documents concerning the development of the outsourcing arrangements and strategies.

Our subsequent analysis and theory building drew on three processes highlighted by Langley (1999): induction, deduction, and inspiration. Our inductive process to analysis drew on the open coding technique (Strauss and Corbin 1990, 1998). Initial coding and conceptualization involved careful reading of, and reflection on, empirical data through which key concepts, themes, and issues were identified and subsequently sorted into categories emerging from the data. We started by organizing the data by client and vendor participants. On the client side, we focused on senior managers, offshoring managers, line managers, and expatriate managers. On the vendors' side, we separated out senior managers, project managers, software engineers/developers, and vendor relationship managers. We examined interview transcripts to identify participants' statements that reflected interpretations surrounding the initial formation and subsequent development of the offshoring relationship. We also examined the changing contexts within which the relationship developed over time, and identified key events in the evolution of the offshoring arrangements (see Arino and De la Torre 1998; Langley 1999). Two researchers independently used the qualitative software program, Nudist, as an aid in the analysis process. Among others, trust and control were dominant themes identified as critical in the on-going development of the offshoring relationship. We subsequently went back to the literature to explore theories of institutionalization and legitimacy as there was a good fit between the underlying themes and this literature (see Boudreau and Robey 2005).

\section{TRUST AND STRATEGIC ACTION IN MANAGING LEGITIMACY}

In this section, we present our case findings highlighting the strategic action adopted by Globalco's top managers and ORD directors in managing legitimacy of the offshoring 
relationship. Four main challenges were identified, namely: gaining legitimacy, maintaining legitimacy, building legitimacy, and repairing legitimacy.

First, early on in the evolution of the relationship, we identified strategies and activities introduced to gain legitimacy for offshoring. In keeping with our theoretical approach, we also identified the reactions of other audiences within Globalco and the vendor firms to the concept of offshoring. Second, we identified actors' strategies to maintain legitimacy and audience reactions. Third, despite challenges, top management sought to further build legitimacy toward offshoring, which was now viewed as a competitive necessity to support their hi-tech strategy. Fourth, as delegitimation set in due to persistent performance and customer risk, ORD and line managers sought to repair legitimacy.

Below, we discuss the strategic action adopted by proponents, the reactions and interactions with other audiences, and the role of trust in managing these legitimacy challenges.

\subsection{Gaining Legitimacy}

Table 1 summarizes the strategic actions adopted in gaining legitimacy for offshoring as a discursive concept and the role of trust in this endeavor. Below, we elaborate on the strategic actions and subsequently synthesize the role of different dimensions of trust.

Two senior Globalco managers of Indian origin led a taskforce to develop an offshoring feasibility project, which would examine how Globalco could increase R\&D productivity and reduce time to market. A successful offshoring strategy was expected to provide Globalco with the flexibility to focus their resources on strategic areas such as the development of new products for new markets.

The CEO at the time, along with a top manager lent crucial support for offshoring to many countries including India. As a founding member of ORD explained,

Table 1. Role of Trust and Strategic Action in Gaining Legitimacy

\begin{tabular}{|c|c|c|}
\hline $\begin{array}{l}\text { Legitimacy } \\
\text { Management } \\
\text { Challenge }\end{array}$ & Strategic Action & Role of Trust \\
\hline $\begin{array}{c}\text { Gaining } \\
\text { Legitimacy }\end{array}$ & $\begin{array}{l}\text { Offshoring feasibility project } \\
\text { Budget structures and ORD office set } \\
\text { up } \\
\text { ORD as brokers develop knowledge of } \\
\text { vendors capabilities and sell to line } \\
\text { managers } \\
\text { Line managers offer independent low } \\
\text { risk tasks to Indian vendors }\end{array}$ & 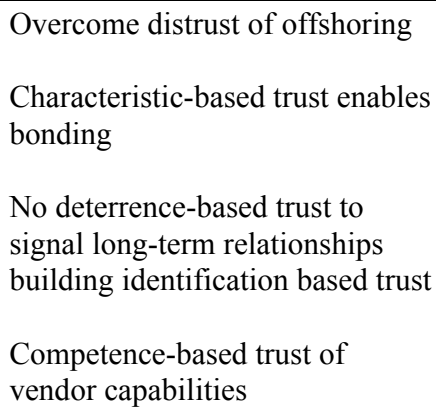 \\
\hline
\end{tabular}


The CEO made the corporation look outside...we were to stay lean and mean and go out and get the best from the world...[we] check[ed] out the viability of India... as the company's brain power, problem solver for research...not replacing MIS.

The initial rationale for offshoring strategy was access to resources, in particular "people with good minds and excellent software skills and low cost." Globalco's vision was recognized as distinctive in the Indian software industry.Indian vendors readily accepted offshoring as legitimate and supportive of their goals of going beyond being mere suppliers toward true partnership. As an Indian vendor senior manager affirmed,

In a nutshell I have seen how they have had (from the beginning) essentially a bigger vision, a bigger goal in mind rather than use India as a cheap resource. They [Globalco] have never projected India as a place for cheap resource.

Gaining legitimacy for offshoring among Globalco line managers and staff was challenging and slow at the beginning. Offshoring was neither desirable nor appropriate to Globalco staff, who were protectionist of local jobs. The senior manager of Indian origin within Globalco who founded the internal offshoring unit explained, "The [key] issue in the early days was that of acceptance of the concept of offshoring by the organization." As important a challenge was the "not invented here" attitude that staff held as a result of their perceived technical superiority. The CEO tried to shift these attitudes, as an ORD director commented, "He tried to get rid of poor attitudes and promoted the idea that just because it is a poor country we shouldn't expect to lower [our] standards."

By addressing directly the negative bias held by Globalco staff, the CEO and top management worked hard at bringing discursive legitimacy to offshoring and promoting the importance of looking for resources outside the firm. The CEO also provided financial support for a feasibility study on offshoring to India, budgeted funds specifically for offshoring, and required managers to declare their offshoring goals and objectives in their budgeting process.

ORD was started up by four directors, two of whom were of Indian origin. ORD was charged with the responsibility to implement and develop offshoring at Globalco. From the beginning, their broker role was crucial to gain legitimacy for offshoring in India: "We had to achieve credibility with internal line managers and be trusted by Indian vendors." Establishing their own credibility with managers was necessary to develop trustworthiness of ORD as an entity. Their role as "lubricant and shock absorber" also focused on "taking the awkardness out of working in India." They made frequent visits to India, gaining an in-depth knowledge of the Indian vendors' skills and capabilities. In their broker role, they subsequently promoted and matched different vendor capabilities to Globalco labs around the world.

The Indian champions setting up ORD at Globalco were keen to contribute to the development of "mother India," and established trust and commitment with the Indian vendors. As a senior manager of an Indian vendor confirmed, "There was a commitment to the relationships with the four partners and a focus on raising the standards as to what is achievable in India, not just undercutting costs."

Standard vendor contracts billed on time and materials were developed between Globalco and the vendor firms. As a founding Indian director of offshoring noted, the 
emphasis of the contracts was on rewards, as penalties signaled mistrust: "We didn't put penalty clauses in the contract.... we drove it by rewards."

After the initial introduction of Indian vendors by a member of the ORD team, champion line managers of Globalco labs initiated offshoring relationships with those vendor firms who met the necessary criteria and best supported their business strategy. These contracts were initially for independent stand-alone tasks such as program testing and bug fixing. Such tasks were perceived to be of relatively low risk and required low levels of direct, face-to-face communication with the Globalco lab. Indian vendors would send the completed tasks electronically to Globalco for testing and integration.

Within a year, the strategy of taking advantage of the economic brain power in India was heralded as a good one. Indian software developers had proved their raw competence and gained a reputation for superior technical talent. The Globalco line managers trusted Indian developers to perform independent tasks, and this early success was critical to establish legitimacy for offshoring and the ORD entity. Line managers were keen to further develop the relationship and gave Indian partners increased responsibility to perform complex and interdependent tasks as part of global project teams. The additional work tasks now included a broader range of activities, including coding and low level design, which required in-depth domain knowledge of telecommunications and Globalco's proprietary products and languages.

Globalco facilitated these new working relationships by improving connectivity and communication, upgrading the infrastructure to two $64 \mathrm{~KB}$ links to enable voice and data paths. Vendors also increased their investment and risk in the relationship, for example, by expanding their premises and ramping up their workforce in anticipation of increased business with Globalco, as explained by an vendor CEO, "They take you into their plans, and then on the basis of these plans, they ask you to bid what you can do for their plans.... The whole organization is very open, once you are taken into their club." The successful efforts by ORD to match vendors with labs and to facilitate growth in the nature and scope of offshoring activities were significant in further gaining legitimacy of vendors for offshoring.

A number of dimensions of trust played an important role in facilitating the abovementioned strategic actions towards gaining legitimacy. First, top managers and ORD sought to overcome initial mistrust and gain legitimacy for offshoring through discursive strategies and mobilizing resources. Second, characteristic-based trust between Globalco managers of Indian origin and their fellow countrymen in Indian vendor firms enabled bonding between these organizational units. Further, a deliberate strategy by the ORD managers to avoid deterrents-based trust, in particular not to include penalty clauses in contracts, was designed to build long-term relationships and build identification-based trust toward Indian vendors' values and goals of true partnership and moving up the value chain. Fourth, competence-based trust between line managers and Indian vendors furthered the gaining of legitimacy as line managers developed knowledge about the capabilities and technical prowess of vendors.

\subsection{Maintaining Legitimacy}

Table 2 summarizes the strategic actions adopted in maintaining legitimacy during subsequent interactions, and highlights the role of trust in this process. Below, we start by elaborating the strategic actions deployed and then discuss the role of different dimensions of trust. 
Table 2. Role of Trust and Strategic Action in Maintaining Legitimacy

\begin{tabular}{|c|c|c|}
\hline $\begin{array}{l}\text { Legitimacy } \\
\text { Management } \\
\text { Challenge }\end{array}$ & Strategic Action & Role of Trust \\
\hline $\begin{array}{l}\text { Maintaining } \\
\text { Legitimacy }\end{array}$ & $\begin{array}{l}\text { ORD implement management prac- } \\
\text { tices and personnel to support } \\
\text { expanded form of offshoring } \\
\text { ORD introduce/impose Western } \\
\text { human resources practices to } \\
\text { manage attrition }\end{array}$ & $\begin{array}{l}\text { Goodwill trust by both parties to } \\
\text { extend tasks and develop } \\
\text { relationship } \\
\text { Systems trust to further offshoring } \\
\text { activities } \\
\text { Micromanage to make up for lack of } \\
\text { competence based trust } \\
\text { Control through systems of expertise } \\
\text { and people at access points }\end{array}$ \\
\hline
\end{tabular}

Following the change in the nature and type of offshoring activities involving new interactions, there was a new challenge to maintaining legitimacy. These activities involved new interactions, which now had to be deemed trustworthy and legitimate in their own right. ORD responded by inculcating a number of their management practices and processes to support Indian vendors in working effectively as global team members. This included technical training on particular Globalco technologies and management practices.

Despite the introduction of a number of coordinating mechanisms, signs of delegitimation soon became apparent. Line managers started to complain about a perceived loss of control over project timetables and delays from the vendors, which were threatening customer satisfaction. Globalco line managers accused the Indian managers of poor project management practices involving late deliverables, which impacted the perceived quality of their work:

One of the things we like are no surprises...If you [are] not going to deliver on a certain time-we want to know it as soon as you know it. Not the day before a project is to be delivered...it's not that...the development partners aren't good...they don't like disappointing.

A recurrent problem that plagued projects was the attrition of talented Indian software developers. Three different types of attrition were identified as persisting in the relationship. The first type was the emigration of developers from partner firms to the United States. Indian firms planned for this attrition by creating a buffer through over staffing projects. The second type of attrition stemmed from developers moving across different Globalco projects within the vendor firm, while the third type involved the movement of developers from Globalco projects to other client work within the firm. Vendor managers explained these actions of attrition by emphasizing the need for them as a company to meet the career development of their staff.

In the eyes of line managers and ORD, these performance and customer risk problems were starting to delegitimize offshoring as desirable and appropriate. Globalco's line managers reacted by being cautious as to the level and type of work they provided 
to Indian vendors: "The clients are afraid of giving too much of the critical deliveries to India because if the key guy goes away they are behind the ball, there is no recovery plan." Line managers also attempted to "de-risk" by micromanaging vendor's work. By monitoring and controlling local developments at a distance, they hoped to ensure that project deadlines and key deliverables were met.

In further efforts to maintain legitimacy of offshoring, ORD mediated between the line managers and Indian vendors and attempted to introduce a range of human resources practices to manage attrition, even though vendors felt attrition was a part of the Indian work landscape with which they had to learn to live. ORD also required vendors to use "gold awards" for retention of key resources, and requested vendors to carry out an employee satisfaction survey they had designed, which the largest vendor flatly rejected as undermining local forms of knowledge and control. In an attempt by ORD to gain compliance with procedures, senior managers were posted to each of the vendor's sites to influence their systems.

Vendors were willing to endure these systems of control as they trusted Globalco to help them meet their goals and interests in moving up the value chain. Furthermore, Globalco also paid very well initially and was genuinely interested in them doing highend strategic work, which contributed to the mainstream of Globalco's work as opposed to the industry norm of replacing business MIS.

However, over time, vendors were adversely affected by the significant "churn" of new product development experienced by Globalco and the industry at large. They experienced significant manpower planning challenges involving the ramp up and disbanding of staff with the birth and death of projects. These dynamic cycles increased vendor overheads in "shadowing" key resources on projects, and this adversely affected the once-attractive profit potential of Globalco contracts.

A number of dimensions of trust played an important role in facilitating the strategic actions adopted in responding to the challenge of maintaining legitimacy. First, the successful legitimacy building efforts stimulated significant goodwill trust, demonstrated by the increasing level of infrastructure investment to extend offshoring activities. From Globalco's perspective, goodwill trust in the relationship was evident due to the fact that, while the partnership remained a legal contract it was much more similar to a joint venture in its operationalization. Second, trust in systems of expertise was introduced to support the expanded set of offshoring activities. Despite these efforts by ORD to lubricate the continued growth of offshoring activities, line managers did not build systems trust in vendors' interactive offshoring activities, often complaining of unacceptable performance and customer risk and responded by micromanaging vendors' efforts. Third, ORD managers tried to build vendors' trust in different systems of expertise (e.g., HR mechanisms) in attempts to control and manage attrition. For example, ORD introduced expatriate postings within vendor firms to be access points to facilitate or control the reembedding of systems of expertise.

\subsection{Building Legitimacy}

Table 3 summarizes the strategic actions adopted by top management in building legitimacy during subsequent interactions, and highlights the associated role of trust. Below, we start by elaborating strategic actions and then synthesize the role of different dimensions of trust at play in building legitimacy. 
Table 3. Role of Trust and Strategic Action in Building Legitimacy

\begin{tabular}{|c|l|l|}
\hline $\begin{array}{c}\text { Legitimacy } \\
\text { Management } \\
\text { Strategy }\end{array}$ & \multicolumn{1}{|c|}{ Strategic Action } & \multicolumn{1}{c|}{ Role of Trust } \\
\hline $\begin{array}{c}\text { Building } \\
\text { Legitimacy }\end{array}$ & $\begin{array}{l}\text { Top management encourage vendor } \\
\text { ownership of mature technologies }\end{array}$ & $\begin{array}{l}\text { Building and reciprocating } \\
\text { identification based trust }\end{array}$ \\
& $\begin{array}{l}\text { Discursive legitimacy of offshoring by } \\
\text { bestowing partners with "sister lab" and } \\
\text { "global lab" status }\end{array}$ & $\begin{array}{l}\text { Top management control requires } \\
\text { increased risk-taking }\end{array}$ \\
\hline
\end{tabular}

Despite the above-mentioned strains of maintaining legitimacy, opportunities emerged to further build offshoring. First, the dramatic contextual changes in the telecommunications sector led Globalco's top management to strategically undertake a rightangle turn toward Internet-based development, and this provided a new impetus for the future potential of offshoring activities. Top managers provided further investments in infrastructure to allow vendors to "almost" function as a "global lab," and rhetorically demonstrated commitment and increased legitimacy for offshoring by conferring "sister lab" status to Indian vendors.

In response to these new opportunities and challenges, line managers started to rely on vendors to take responsibility for code ownership, new product releases, and market ownership of mature technologies so as to free themselves up to work on leading edge technology developments. The discursive legitimacy of sister lab status stirred significant optimism of a true partnership among Indian vendors as suggested, by a vice president: "But I believe that the world is moving towards...partnering as something which is the call of the day, in the true sense of partnering.... I believe that Globalco is definitely a partner of choice to us." Vendors readily embraced this shift toward partnership and also the move away from "tool work to include products and markets." This evolution of the relationship gained legitimacy with Indian vendors, for whom the meaning of offshoring was aligned with their goals and interests.

In building legitimacy, two key dimensions of trust were salient. First, identification-based trust was reciprocated and built in response to the strategic actions and discursive legitimacy, which furthered the offshoring relationship. Second, top management displayed more trust through an increased appetite for risk taking.

\subsection{Repairing Legitimacy}

Table 4 summarizes the strategic actions adopted in supporting the right-angle turn and the role of trust in surmounting this legitimacy challenge. Below, we start by elaborating strategic actions and then synthesize the role of different dimensions of trust.

Globalco line managers continued to complain about attrition and its effects on project management and customer satisfaction. Their concerns were accentuated in light of the movement from code to product ownership. ORD directors remained unhappy with the efforts of vendors in addressing this ongoing problem. Even more seriously for the relationship, they became highly suspicious of vendors' low incentive levels to deal with 
Table 4. Role of Trust and Strategic Action in Repairing Legitimacy

\begin{tabular}{|c|c|c|}
\hline $\begin{array}{c}\text { Legitimacy } \\
\text { Management } \\
\text { Challenge }\end{array}$ & Strategic Action & Role of Trust \\
\hline $\begin{array}{l}\text { Repairing } \\
\text { Legitimacy }\end{array}$ & $\begin{array}{l}\text { ORD implement an experience based pay } \\
\text { model } \\
\text { Senior Globalco managers instill Western } \\
\text { culture and work practices in vendor firms } \\
\text { ORD introduces an Indian offshore } \\
\text { development center }\end{array}$ & $\begin{array}{l}\text { Perceived lack of proactivity } \\
\text { stymies competence trust } \\
\text { Goodwill trust declines over } \\
\text { new charging model } \\
\text { Introduce new systems of } \\
\text { control to reduce risk and repair } \\
\text { competence trust }\end{array}$ \\
\hline
\end{tabular}

attrition but rather a curious willingness to merely live with the problem. ORD perceived a zero-sum game and alleged that highly experienced staff leaving projects were being replaced by fresh, inexperienced recruits at full replacement cost to Globalco. An offshoring director hinted at the potential financial gains the vendors could accrue by adopting such strategies:

The current strategy for controlling attrition doesn't manage productivity but is merely a simple substitution principle. A new person is substituted for an old, experienced worker in Globalco technology.... So in that respect the attrition and losses are good for the contractors, the partners.

This view of vendors' charging policy led to mistrust and challenged the desirability and appropriateness of offshoring to provide low costs and provide further revenue to support Globalco's right angle turn. These concerns of moral and pragmatic legitimacy brought into question the appropriateness of the entity responsible for organizing offshoring across the network of client-vendor organizations.

While vendors sought to justify the performance threats of attrition, ORD directors disassociated Globalco from procedures that were depleting long-term legitimacy reserves. ORD allowed the introduction of penalty clauses in contracts and restructured vendor rates. Instead of being calculated as a linear model based on number of resources, an experience-based pay model was adopted that used tiered rates based on years of experience.

A second challenge Globalco experienced was the perceived lack of proactivity by Indian vendors, which was deemed critical if they were effectively to support Globalco's right-angle turn and access to regional markets.

Repairing legitimacy of offshoring, therefore, involved a rethinking as to the legitimate form required to adequately support the right angle turn. ORD sought professional advice from a consultant and subsequently restructured around an offshore development center (INDCO). It was proposed as an extension of ORD to be located in India, which would leverage and integrate Indian vendor resources. INDCO would specifically be responsible for ownership of leading-edge products that had high customer impact as well as mature products with high customer impact. 
INDCO's strategy for repairing legitimacy included the introduction of subject matter experts to reduce the need for micromanagement by line managers and to eventually facilitate new opportunities for vendors to ultimately move up the value chain. The focus on building an experience base within the vendors was cast as a critical success factor in the de-risking strategy and building legitimacy of offshoring at the interaction level. Globalco theorized that line managers would develop competence trust in Indian vendors, which would lead to less control or micromanagement on their part. As a senior offshoring Director noted,

\section{How do I de-risk? Some companies do this by bodyshopping. This is best done by raising the experience basis, which involves the use of subject matter experts. When the experience basis is low, there is a tendency for Globalco managers to micromanage. In either case, costs are high.}

However, vendors hotly contested the INDCO center proposal, perceiving it as a significant loss of legitimacy for offshoring. They believed the INDCO center would sustain the arm's length vendor relationship, thwarting vendors' desire for true partnership and delaying their ability to move up the value chain.

A number of dimensions of trust played an important role in facilitating the strategic actions adopted in responding to the challenge of repairing legitimacy.

First, a number of perceived risks led to an erosion of trust relations, which challenged legitimacy and led ORD to develop repair strategies. ORD and line managers continued to perceive high levels of performance and customer risk as a result of attrition, and this was only accentuated as they started to transfer product and market ownership to vendors. These concerns, along with beliefs that Indian vendors lacked proactivity, adversely affected the building of competence trust in supporting this expanded set of offshoring activities. Even more seriously, perhaps, was the loss of goodwill trust by ORD over suspicions of the existing charging model, which they deemed to be scandalously inappropriate and a challenge to moral legitimacy (Suchman 1995). The new experience based pay model, however, simultaneously impacted on vendors' goodwill trust in the relationship. Third, ORD attempted to repair legitimacy through restructuring both the concept and entity of offshoring in support of the right-angle turn. INDCO sought to de-risk and build competence trust through the aid of locally based subject matter experts. Vendors interpreted INDCO as a lack of identification trust by Globalco, adversely affecting vendors' goodwill trust. Efforts to rebuild goodwill trust through the joint task force sought to restore legitimacy of offshoring through a process of developing identification-based trust between Globalco and its vendors. These efforts highlighted the tight coupling of trust and legitimacy that pervaded the relationship between vendors and Globalco.

\section{CONCLUSION}

This paper introduces theoretical developments on legitimacy and trust to examine the evolution of offshoring of IT services around global software development. In so doing, we contribute a first step in understanding the role of trust in legitimacy dynamics. 
Our research highlights the different challenges of managing legitimacy, strategic actions that proponents can adopt to respond to these challenges, and the role of trust in the unfolding legitimacy dynamics. For example, even when the concept of offshoring had become legitimated, mistrust that developed over recurrent interactions (e.g., how attrition was managed and the introduction of the experience-based pay model) can call into question the legitimacy of the entity. Repairing legitimacy in this situation led proponents to dramatically restructure, which ultimately led to efforts at enhancing cognitive legitimacy through the joint client-vendor taskforce.

As our case shows, dimensions of trust are developed through interactions between various sets of actors across the different legitimacy management strategies. For example, gaining legitimacy was achieved through interactions between top management, ORD, and line managers who successfully built affect-based trust with vendors. Furthermore, line managers relied heavily on cognition-based trust (in particular, competence-based trust) throughout the evolution of the offshoring arrangement. Maintaining legitimacy was dependent on further building competence-based trust through interactions between line managers and vendors. In addition, system trust (and control) was relied on heavily by ORD during interactions with vendors. Top management's building of legitimacy evoked affect-based trust (in particular identification-based trust) with vendors and highlighted the way groups of actors with various interests depend on different dimensions of trust. ORD's efforts at repairing legitimacy relied on control through restructuring and introducing systems of expertise into vendor firms, which they subsequently resisted and instead sought to establish mutual identification-based trust.

Finally, our case illuminates that legitimacy building is an iterative process (Provan et al. 2004), whose success or failure at any interaction can affect other dimensions of legitimacy, such as calling into question the meaning of the concept of offshoring or restructuring the entity. Further research is needed to validate and build on our findings, and deepen our understanding of the evolution of offshoring arrangements. Nonetheless, we believe our conceptual developments on legitimacy management and trust are a useful starting point in this direction and may be a helpful guide for managers of both client and vendor firms involved with institutionalizing offshoring of IT services.

\section{References}

Aldrich, H. E., and Fiol, C. M. 1994. "Fools Rush In? The Institutional Context of Industry Creation," Academy of Management Review (19), pp. 645-670.

Arino, A., and De la Torre, J. 1998. "Learning from Failure: Towards an Evolutionary Model of Collaborative Ventures," Organization Science (9), pp. 306-325.

Barber, B. 1983. The Logic and Limits of Trust, New Brunswick, NJ: Rutgers University Press.

Barley, S., and Kunda, G. 2001. "Bringing Work Back In," Organization Science (12)1), pp. 76-96.

Baum, J., and Powell, W. 1995. "Cultivating an Institutional Ecology of Organizations: Comment on Hannan, Carroll, Dundon and Torres," American Sociological Review (60), pp. 529-538.

Boudreau, M.-C., and Robey, D. 2005. "Enacting Integrated Information Theory: A Human Agency Perspective," Organization Science (16:1), pp. 3-18.

Child, J. 1998. "Trust and International Strategic Alliances: The Case of Sino-Foreign Joint Ventures," in Trust Within and Between Organizations: Conceptual Issues and Empirical Applications, C. Lane and R. Bachmann (eds.),Oxford, UK: Oxford University Press. 
Child, J. 2001. "Trust: The Fundamental Bond in Global Collaboration," Organizational Dynamics (29:4), pp. 274-288.

Colyvas, J., and Powell, W. 2006. "Roads to Institutionalization: The Remaking of Boundaries Between Public and Private Science," Research in Organizational Behavior (25), pp. 305-353.

Das, T. K., and Teng, B. 2001. "Instabilities of Strategic Alliances: An International Tensions Perspective," Organization Science (11:1), pp. 77-101.

Dasgupta, P. 1988. "Trust as a Commodity," in Trust: Making and Breaking Cooperative Relations, D.Gambetta (ed.), Oxford, UK: Blackwell, pp. 49-72.

de Rond, M., and Bouchikhi, H. 2004. "Dialectics of Strategic Alliances," Organization Science (15), pp. 56-69.

DiMaggio, P. J., and Powell, W. W. 1991. The New Institutionalism in Organizational Analysis, Chicago: University of Chicago Press.

Doney, P. M., Cannon, J. P., and Mullen, M. R. 1998. "Understanding the Influence of National Culture on the Development of Trust," Academy of Management Review (23:3), pp. 601-620.

Giddens, A. 1984. The Constitution of Society, Cambridge, UK: Polity Press.

Giddens, A. 1990. The Consequences of Modernity, Cambridge, UK: Polity Press.

Human, S. E., and Provan, K. G. 2000. "Legitimacy Building in the Evolution of Small Firm Multilateral Networks: A Comparative Study of Success and Demise," Administrative Science Quarterly (45), pp. 327-365.

Humphreys, L. 1998. "Trust and the Transformation of Supplier Relations in Indian Industry," in Trust Within and Between Organizations, Conceptual Issues and Empirical Applications, C. Lane and R. Bachmann(eds.), Oxford, UK: Oxford University Press, pp. 214-272.

Jepperson, R. L. 1991. "Institutions, Institutional Effects, and Institutionalism," in The New Institutionalism in Organizational Analysis, W. W. Powell and P. J. DiMaggio (eds.), Chicago: University of Chicago Press, 1991, pp. 143-163.

Langley, A. 1999. "Strategies for Theorizing from Process Data," Academy Management Review (24:4), pp. 691-710.

Lewicki, R. J., and Bunker, B. B. 1995. "Trust in Relationships: A Model of Trust Development and Decline," in Conflict, Cooperation, and Justice, B. B. Bunker and J. Z. Rubin (eds.), San Francisco: Jossey-Bass, pp. 133-173.

Luhmann, N. 1979. Trust and Power, Chichester, UK: John Wiley \& Sons.

Mayer, R. C., Davis, J. H., and Shoorman, D. 1995. "An Integrative Model of Organizational Trust," Academy of Management Review (20:3), pp. 709-734.

NASSCOM. 2005. "Indian ITES-BPO Industry: NASSCOM Analysis," (http://www. creativebpo.com/IndianITES-BPOFactsheet.pdf).

Newell, S., and Swan, J. 2000. "Trust and Inter-Organizational Networking," Human Relations, (53:10), pp. 1287-1328.

Nicholson, B., and Sahay, S. 2001. "Some Political and Cultural Issues in the Globalization of Software Development: Case Experience from Britain and India" Information and Organization (11), pp. 25-43.

Orlikowski, W. J. 2000. "Using Technology and Constituting Structures: A Practice Lens for Studying Technology in Organizations," Organization Science (11:4), pp. 404-428.

Pettigrew, A. 1990. "Longitudinal Field Research on Change: Theory and Practice," Organization Science (1:3), pp. 267-292.

Provan, K. G., Lamb, G., and Doyle, M. 2004. "Building Legitimacy and the Early Growth of Health Networks for the Uninsured," Health Care Management Review (29:2), pp. 117-128.

Ring, P. S. 1996. "Fragile and Resilient Trust and Their Roles in Economic Exchange," Business \& Society (35:2), pp. 148-175.

Ring, P. S., and Van de Ven, A. H. 2001. "Structuring Cooperative Relationships Between Organizations," Strategic Management Journal (13), pp. 483-498. 
Sabherwal, R. 1999. "The Role of Trust in Outsourced IS Development Projects," Communications of the ACM (42:2), pp. 80-86.

Sahay, S., Nicholson, B., and Krishna, S. 2003. Global IT Outsourcing: Software Development Across Borders, Cambridge, UK: Cambridge University Press.

Shapiro, D., Sheppard, B. H., and Cheraskin, L. 1992. "Business on a Handshake," Negotiation Journal (8), pp. 365-377.

Strauss, A. L., and Corbin, J. 1990. Basics of Qualitative Research: Grounded Theory, Procedures, and Techniques, Newbury Park, CA: Sage Publications.

Strauss, A., and Corbin, J. 1998. Basics of Qualitative Research Techniques and Procedures for Developing Grounded Theory ( $2^{\text {nd }}$ ed.), London: Sage Publications.

Suchman, M. 1998. "Managing Legitimacy: Strategic and Institutional Approaches," Academy of Management Review (20:3), pp. 571-610.

Suddaby, R., and Greenwood, R. 2005. "Rhetorical Strategies of Legitimacy," Administrative Science Quarterly (50), pp. 35-67.

Sydow, J., and Windeler, A. 1998. "Organizing and Evaluating Interfirm Networks: A Structurationist Perspective on Network Processes," Organization Science (9:3), 265-284.

Williamson, O. E. 1985. The Economic Institutions of Capitalism, New York: Free Press.

Zucker, L. G. 1986. "Production of Trust: Institutional Sources of Economic Structure 18401920," Research in Organizational Behaviour (8), pp. 53-111.

\section{About the Authors}

Michael Barrett is the director of the M.Phil. program on Innovation, Strategy, and Organization at the Judge Business School, University of Cambridge. His research interests include Information technology and service innovation; IT implementation and organizational change; and IS services outsourcing and globalization. Michael is an associate editor for MIS Quarterly and Information Systems Research and a member of the editorial boards of Organization Science, Information and Organization, and Journal of the Association of Information Systems. He has worked as an IS consultant with Oracle Canada Corp, and in production management with Colgate Palmolive Jamaica Ltd. Michael can be reached at m.barrett@jbs.cam.ac.uk.

Bob Hinings is Professor Emeritus in the Department of Strategic Management and Organization, School of Business, University of Alberta, and Senior Research Fellow in the Centre for Entrepreneurship and Family Enterprise. He is currently carrying out research on strategic organizational change in professional service firms, healthcare, and the Canadian wine industry. He is a Fellow of the Royal Society of Canada, a Fellow of the U.S. Academy of Management, and an Honorary Member of the European Group for Organizational Studies. He has been a recipient of the Distinguished Scholar Award from the Organization and Management Theory Division of the U.S. Academy of Management. Bob can be reached at chinings@ualberta.ca.

Eivor Oborn is a senior research associate at the Judge Business School where she earned her Ph.D. Her research interests are broadly concerned with knowledge development in multidisciplinary teams for service innovation, and have centered on multi-professional healthcare and software development teams. She is also studying new technology adoption and diffusion within the UK National Health Service and the processes of legitimising change within institutions. Eivor can be reached at emdo2@hermes.cam.ac.uk. 